\title{
Case study O: Political economy of social protection in Kenya
}

\author{
Barbara Rohregger
}

\section{INTRODUCTION}

With the roll out of social protection programmes to national scale, questions about implementation and delivery move more and more into the centre of debate (e.g. UNDP 2020; UNDP and UNCDF 2014; Kramon 2019). This concerns in particular the local level, where key processes of implementation are taking place, but where at the same time institutional, operational and financial capacities are often the weakest. While social protection programmes are usually based on a clearly defined set of operational rules and regulations - usually set out in a programme manual - in practice these processes often tend to look quite different. Although many social protection programmes have explicitly excluded traditional authorities from playing an active role in programme delivery, there is ample evidence from across countries that in many local contexts, these 'informal institutions' continue to play an important role in the delivery of social protection programmes. This case study on Kenya's cash transfer programmes for orphans and vulnerable children suggests that this influence is not necessarily negative, as suggested by a range of authors who vividly describe how traditional authorities successfully undermine formal programme set-ups by manipulating rules and regulations in their favour, thereby fostering the very inequalities that social protection programmes aim to address (e.g. Pellissery 2005; Casson et al. 2010; Crost and Kambhampati 2010; Marcesse 2018). Instead, the case study shows that traditional authorities - in the face of weak or limited public administrative structures - may also assume a proactive and complementary role in delivering pro-poor social policies. Contextual features, such as the degree of decentralization of programmes, the demographic or geographic setting are important determinants in this respect.

The case study sets out with a short overview of the Cash Transfer for Orphaned and Vulnerable Children (CT-OVC) programme before presenting the empirical evidence describing and assessing the role of traditional authorities in programme delivery. The case study concludes proposing a more differentiated perspective on traditional authorities and their role with regards to the implementation of social protection policies, especially where the institutional capacity is particularly weak.

\section{CASH TRANSFER FOR ORPHANED AND VULNERABLE CHILDREN PROGRAMME IN KENYA}

CT-OVC is the oldest and largest of Kenya's cash transfer programmes initiated in 2004 as a response to the rising number of orphans and vulnerable children as a result of HIV/AIDS (MLEAA 2016). Supporting families living with OVCs with regular unconditional cash transfers, it aims at encouraging the fostering and retention of OVCs within their families and 
communities as well as promoting human capital development of children and carer households (National Safety Net Program n.d.). The countrywide programme provides KES 2,000 per household per month (around USD 19) paid on a bi-monthly basis.

The programme is implemented on a national scale through the sub-national structures of the ministry. A programme manual sets out a clear and detailed operational structure and accompanying rules and regulations which are regularly updated, including the explicit exclusion of traditional authorities, including sub-chiefs and community elders, from having any role in the programme implementation.

\section{ROLE OF LOCAL INSTITUTIONS}

Despite these formal rules, evidence suggests that chiefs, sub-chiefs and community elders are routinely at the centre stage of core implementation processes at local level, including targeting, enrolment, delivery, monitoring, awareness and information, data collection and grievance and redress. In fact, for many local civil servants in charge of implementing the programme and interacting with the communities on a day-to-day basis, traditional authorities are a key partner in programme delivery. While they indeed manipulate programme rules or even compete with them, they also have a proactive role by complementing and sometimes even substituting lacking or badly functioning public delivery systems (Helmke and Levitsky 2004).

Despite the fact that they are officially excluded from targeting processes, traditional authorities continue to play an important role: given their knowledge of an area it is common practice in the context of the CT-OVC to include local leaders (village elders) in the targeting process in an advisory function. This may result in highly ambivalent outcomes, as traditional authorities may exert a considerable influence as to who is included in the programme or not. Local public servants and potential beneficiaries complained a lot about chiefs, sub-chiefs and community elders and how they were skewing targeting mechanisms in their favour, enlisting family members or kinsmen or non-eligible persons in return for personal, material or political favours.

This competitive relationship with formal institutions has even led to open conflicts with the formal CT-OVC programme management: one of the formal administrative roles of traditional authorities in Kenya is the issuing of identification (ID) cards at local level. Holding an ID document is a core precondition in order to get enrolled in the programme and access the transfer in the bank. In border areas close to Uganda where cross-border migration is an integral part of people's livelihoods, chiefs refused to issue ID cards to some beneficiaries claiming that, due to their migration background, they were non-Kenyans and thus not eligible to receive the benefits. Only through the intervention of the CT-OVC management could this issue be resolved and could the formal programme rules be re-established.

However, informal institutions do not only produce negative outcomes, but may also take on a proactive and pro-poor role with regards to targeting processes. This is for example the case in areas where the population and villages, and consequently also the CT-OVC beneficiaries, are dispersed over large territories. In this situation it is challenging for the Location Committees in charge of carrying out targeting processes and typically constituted in the main community to identify all potential beneficiaries, especially if they are living in small sub-communities or hamlets that are far away from the main community. Often they did 
not have the means or simply did not bother to go there. In these circumstances, the role of sub-chiefs (despite being against formal requirements and rules) representing these hamlets and sub-communities was decisive in bringing potential beneficiaries to the attention of the targeting committee and enabling them to apply and get enrolled. In some circumstances, traditional authorities even took over the entire targeting process. The CT-OVC targeting process foresees a two-step model based on geographic and community-based targeting. The former was soon abandoned by the central authority in favour of geographic targeting guided by a politically motivated regionalism rather than vulnerability, which guaranteed each region and county an equal share of CT-OVC beneficiaries. As a result, some regions and counties were assigned only a very limited number of beneficiaries. In this situation and given the overall constrained capacity situation, costs for initiating a complex targeting process to identify a handful of beneficiaries were considered much too high by local civil servants; instead, they simply asked traditional authorities to identify eligible beneficiaries.

Grievance and redress is another important programme aspect, where 'informal' institutions play an important role. According to the CT-OVC manual, the Beneficiary Welfare Committee (BWC) is supposed to be the local grievance and redress mechanism for CT-OVC beneficiaries. In many villages, however, complaints with regards to the programme, including targeting, enrolment or pay-out, were mainly handled by the chief and the council or village elders. Given their long history as highly experienced and trusted dispute settlement institutions, the Beneficiary Welfare Committees simply could not compete; unless it was about very complicated issues that needed the intervention of a higher level, traditional authorities were described as much faster and cost-efficient in providing solutions than the newly established grievance structure by the programme.

Traditional authorities have a key function in facilitating community meetings (called barazas) which play a key role in carrying out targeting processes, disseminating information, organizing enrolment and pay-outs. During interviews, civil servants emphasized again and again the importance of traditional authorities in facilitating these meetings. This related on the one hand to their organizational capacity. Especially in rural areas, traditional authorities are highly trusted and engrained institutions. This renders them highly effective and efficient instruments in order to realize programme objectives, for example by organizing meetings, making sure that everyone shows up or collecting and disseminating information in an appropriate way. Especially where their operational and institutional capacity is low, civil servants simply need them in order to deliver services. On the other hand, this relates to the role of traditional authorities as powerful local gate-keepers who are almost impossible for public institutions to simply by-pass - even if formal rules say otherwise: 'You cannot do anything without the chief. You say you do away with them, you are doomed.'

\section{FACTORS INFLUENCING THE ROLE OF TRADITIONAL INSTITUTIONS}

The degree to which the chiefs and traditional authorities may exercise their function as gate-keepers of social protection varies across geographic areas and time, contradicting the

Interview 166: local civil servant. 
common notion of social protection programmes being implemented evenly across geographic and political entities. Evidence seems to suggest a strong correlation between the availability of human and technical resources at the local administrative level and their capacity to 'compete' with local traditional authorities in mediating access to public services. Where public service delivery systems function better, there is less room for traditional authorities in programme delivery.

Geography also seems to play a role: in rural areas, where administrative units cover huge and scarcely populated areas, transaction costs for programme implementation are much higher. Local civil servants complained about their heavy workload with the cash transfer programme being just one among many other child-related projects they are supposed to manage. Mobile devices often do not work rendering communication a challenge. Many also lack the operational capacity, such as transport or fuel to carry out their work. In this situation, traditional authorities become an important partner in keeping programmes running.

However, the extent to which traditional authorities can influence programme outcomes is not only the result of a malfunctioning formal administrative system or geographic as well as demographic conditions. In the rural context, traditional authorities make up an important part of the local institutional fabric and community structure, which civil servants simply cannot ignore. This is even more the case, as the CT-OVC as many other social protection programmes tends to propagate a participatory approach foreseeing a certain degree of involvement on the part of the community. In towns, the situation is different. Traditional authorities continue to play a role, but their power is much diluted by a lower degree of social cohesion. Also, in urban areas political parties are much more influential and political competition for votes much stronger. In this context, CT-OVC institutions seem to be able to impose themselves better, as more checks and balances seem to be in place which appear to guarantee better compliance to the programme rules (see also Kramon 2019; Zucco, Jr. 2013).

Time and the availability of information are yet other factors that influence the way formal and informal institutions interact in delivering the CT-OVC. Where the CT-OVC is in place for longer, formal institutional rules and regulations appear to become more ingrained. Information appears to have a decisive role in this regard: the longer programmes are in place, the better people tend to be informed about the programmes' main operational features, enabling beneficiaries to critically question and sanction potentially unruly informal behaviour and turn to formal CT-OVC institutions to raise complaints and claim their rights. This would, eventually, lead to a stronger institutionalization of formal institutions versus informal ones. However, the shift in institutional equilibrium from informal institutions towards formalized ones does not seem to be automatic or irreversible. A range of interview partners complained about the growing politicization of the CT-OVC as a result of the devolution processes since 2010 which has increased traditional authorities' influence at local level, resulting in a reverse trend in the local institutional equilibria. Civil servants at the local level expressed their deep concern about the fact that with ongoing devolution processes, the CT-OVC programme would be increasingly exposed and even superimposed by 'non-programme rules' (Kramon 2019), i.e. access criteria dominated by political interests and favouritism - with negative consequences for the poor. 


\section{CONCLUDING REMARKS}

Traditional authorities play an important - though ambiguous - role in the delivery of social policies, oscillating between complementing and even substituting constrained formal programme structures on the one hand, and competing and undermining them on the other. Evidence suggests that this will not change in the near future. This is most apparent in lowand middle-income countries where formal institutions tend to be weaker and implementation processes are taking place in a hybrid and highly dynamic institutional setting that transcends formal and informal institutions.

Rather than focusing on trying to limit the influence of informal institutions by - largely unsuccessfully - excluding them from formal programmatic processes, evidence suggests that research and policy need to take a closer and more critical look at how formal and informal institutions are actually intertwined in the delivery of pro-poor public services. This would also allow developing strategies on how they can possibly be better aligned in order to produce more convergent, pro-poor policy outcomes at local level.

\section{REFERENCES}

Casson, M., M. Della Giusta and U.S. Kambhampati (2010). Formal and informal institutions and development. World Development 38 (2), 137-41.

Crost, B. and U.S. Kambhampati (2010). Political market characteristics and the provision of educational infrastructure in north India. World Development 38 (2), 195-204.

Helmke, G. and S. Levitsky (2004). Informal institutions and comparative politics: A research agenda. Perspectives on Politics 2 (4), 725-40.

Kramon, E. (2019). The local politics of social protection: Programmatic versus non-programmatic distributive politics in Kenya's cash transfer programmes. Final Report. International Growth Centre, London School of Economics (S-47413-KEN-1).

Marcesse, T. (2018). Public policy reform and informal institutions: The political articulation of the demand for work in rural India. World Development 103, 284-96.

Ministry of Labour and East-African Affairs (MLEAA) (2016). Inua jamii: Towards a more effective national safety net for Kenya. Progress Report. Nairobi: MLEAA.

National Safety Net Program (n.d.). Cash transfer for orphans and vulnerable children (CT-OVC). www .socialprotection.or.ke/social-protection-components/social-assistance/national-safety-net-program/ cash-transfer-for-orphans-and-vulnerable-children-ct-ovc

Pellissery, S. (2005). Local determinants of exclusion and inclusion in rural public works programmes: A political economy approach. International Journal of Rural Management 1 (2), 167-84.

United Nations Development Programme (UNDP) (2020). The Institutionalization of Social Assistance in Africa. New York: UNDP.

United Nations Development Programme (UNDP) and United Nations Community Development Fund (UNCDF) (2014). Strengthening the Governance of Social Protection: The Role of Local Government. Regional Analysis. Bangkok: UNDP.

Zucco, Jr., C. (2013). When payouts pay off: Conditional cash transfers and voting behavior in Brazil 2002-10. American Journal of Political Science 57 (4), 810-22. 